\title{
Teaching, Leadership and School Culture - from loose to tight couplings
}

\author{
Steen Beck \\ Lars Frode Frederiksen ${ }^{1}$ \\ Institute of Philosophy, Pedagogic and Study of Religions \\ University of Southern Denmark
}

The Danish upper secondary school system is undergoing remarkable changes these years. The teacher's role and fundamental structures of the organization changes, as comprehensive reforms put new structures into the single school. The reform build new frames of teaching into the everyday life of the teachers and questions arise: What happens when teachers are to implement such thorough reforms, when schools are left with a great many decisions to make and a new working culture to build?

In a four-year research project, the authors of this paper and two colleagues investigate these questions in a sociological, didactical and organizational perspective, using quantitative as well as qualitative methods. Our aim is to contribute with theoretical and empirical considerations focusing on teachers' and managers' behaviour under conditions characterized by pressure from several internal and external stakeholders. In this paper we present empirical findings leading to theoretical perspectives considering teachers' position towards central aspects of the reform and the responses that can be found among managers.

\section{Structures and visions in the 2005 reform}

The 2005-reform of the upper secondary school has been characterized as the most ambitious since the modern upper secondary school was established in $1903^{2}$. Among the most important issues of the very complex reform we will emphasize the following:

- The single class is now to be seen as a kind of unit being carried by central subjects.

The 2005 reform replaces the 1988 reform where the students besides having their basis class could choose several free subjects. The 1988 reform has been called 'the party of the subjects', and from a critical point the fragmentation of the class as a unit made it difficult to create collaboration among teachers about interdisciplinary activities and competence building. The main goal of the 2005 reform can be seen as an attempt to solve these problems. Now the students have to choose a so called "Study Line" which is built around certain subjects. This means that the students are together in a basic class unit almost all the time making teacher collaboration possible. With a rather precise metaphor you may say that the upper secondary school has moved from a 'buffet-school' to a 'menu-school'.

\footnotetext{
${ }^{1}$ This paper is a part of a larger project "Changing teacher roles in light of Upper Secondary School Reform". The project is supported by The Danish National Union of Upper Secondary School Teachers and the Danish Ministry of Education.

Author information for correspondence: Steen Beck (steen.beck@ifpr.sdu.dk) and Lars Frode Frederiksen (frode@ifpr.sdu.dk).

${ }^{2}$ the 3-year Upper Secondary School Leaving Examination (STX), the 3-year Higher Commercial Examination (HHX), and the 3-year Higher Technical Examination (HTX).
} 
- An important main feature in the reform is more interdisciplinary activities, work with competence building and a more flexible way of making schedules.

A central element in the reform is a dimension called General Study Preparation. The purpose of General Study Preparation is double: 1) The students learn how to use the subjects in a more practical manner (for instance project work). 2) The students learn to reflect their own learning process. 10 percent of the lesson time is to be used for General Study Preparation. Another central aspect of the reform is The Study Plan. The purpose of The Study Plan is to make teachers reflect their general work with the competence building in each of their class units. Yet another important feature is the change from year-schedule to what is called yearnorm. The students are not any longer having for instance English lessons three lessons a week, bit will have these lessons in 'blocks' through the semester. This makes a more flexible planning possible. Actually this kind of flexibility was possible before 2005 , but still it should be seen as a product of the reform thinking where flexibility is a main theme.

- The team is the central place to coordinate the teachers' work with the class.

The reform changes the teacher's work radically. Traditionally teachers in the Danish upper secondary school had a large individual autonomy in relation to methods. "One class, one teacher, one subject" was the norm. Collaboration among teachers happened, but more on the basis of free will than as a structural necessity. This has changed. Due to the new dimension, The General Study Preparation and the new organization of class-units in a Study Line, teachers have to collaborate much more than before. Therefore the individualized teacher orientated towards his or her 'own' subject within a relative stabile structure of lessons on a weekly basis is partly replaced with new collaborative structures, which question the 'freedom of method'. The reform emphasizes a systematic and team-organized pedagogic, focusing on the development of students' competences in relation to phenomena as various working methods, progression and metacognition. The changes due to the reform may represent a transfer from "the age of autonomous professional" to "the age of the collegial professional" (Hargreaves 2000).

- The reform creates a much more complex organization than before. Such an organization calls for leadership and consequently, school management is much more focused on today than just 10 years ago.

The traditional school had a very flat structure, the professional bureaucracy was the norm (Mintzberg 1983) and the mutual relationship between teachers and between teachers and leaders was loosely coupled (Weick 1976). Now, the single school is seen as an organizational unit, this does not only demand more organizational consciousness from the single teacher, but also creates new and less egalitarian structures. New kinds of managers emerge (for instance, pedagogical leaders, team leaders and so on) - and the headmaster is seen as a manager in his own right to do the strategic thinking of the organization and not as a "primo inter pares" (the best among equals).

The reform discourse is to be seen as a result of the vision of the knowledge society, making new demands to the working life and accordingly to the kind of knowledge to possess (Gibbons et al. 1994). The shift from qualification oriented teaching aims to competence orientated teaching aims (Qvortrup 2000) is a direct consequence of the vision of lifelong learning, stressing the flexibility and dynamics of the learning subject. In this way the more flexible structure of time schedules in schools can be seen as a preparation for 'spaghetti- 
structures' of the future working life. These elements are indirectly and in a sometimes diffuse manner connected to learning theory (Piaget 2000, Vygotskij 2006, Lave and Wenger 2003), especially different kinds of sociocultural theories. In the reform discourse traditional deductive teaching is being challenged by the idea of a variation of work methods, encouraging more inductive didactical methods. The concept of project work seems to possess a privileged position in this respect.

The implementation of the reform can be seen as a top-down process. It is initiated by the political and ministerial authorities. However, some elements of the reform do correspond with for instance the pedagogic debate and wishes among some teachers and since the mid 90 'ies several pedagogic experiments have taken place in different schools. But still, the subject of the reform discourse is The Ministry of Education, and it is not an exaggeration to say that the radical nature of the reform sent chock waves through schools and teachers when it was first presented. The new organizational structures called for a change of the entire organization culture.

But one thing is to make structural changes and to build up a pedagogical and political discourse from a school external level. Another thing is to carry out the reform in the daily life in schools. One can draw logical and very advanced diagrams on a complex organization, but the culture of the same organization may be quite another issue (Hargreaves 2000). One explanation for this is that there is not only the reform discourse, but also the daily discourse and behind this the fundamental stipulations within a culture - which can be more or less affirmative towards the reform discourse. From a sociological point of view one may say that the new programmes and discourses demand new roles to possess for teachers (Luhmann 2000) - but the degree to which teachers identify with these roles is still to be seen. In any case the result will be a new kind of culture. But what kind of culture will emerge? Is it a culture of involvement? Is it a culture of cynicism? Or is it a more diverged culture?

The main question is:

- How does the reform influence the organization of the schools?

In this paper we will concentrate on five questions:

- How do the teachers respond to the idea about interdisciplinary activities and a variation of working methods?

- How do the teachers respond to the idea of documentation in relation to competence building (The Study Plan)

- How do they respond to the idea of collaboration in teams?

- How do they respond to different aspects of management?

- Which kinds of management can be seen as a consequence of the reform?

\section{Method}

The results presented in this paper is a part of a larger four year project focusing on the changed teacher role as a consequence of the reform of the Danish upper secondary school system.

The methods for gathering empirical data are quantitative as well as qualitative. First step was a questionnaire to a representative part of teachers. The questionnaire was constructed by a presentation of a range of statements concerning teachers' perceptions about teaching 
methods, disciplinary versus cross-disciplinary issues, and perceptions to cross-disciplinary teamwork and management. Teachers' could respond on a four point Likert scale, ranking from a high degree of agreement to a low degree of agreement. We receive answers from about 1800 teachers, which meant a response rate on approximately $60 \%$.

The second phase consists of site visits on sixteen schools with classroom observation and observation of meeting in teams as well as interviews with leaders, teachers and students respectively.

The empirical data is partly the first survey and some examples from the first field study.

\section{Cross disciplinary collaboration and working methods}

An important purpose of the survey was to find out how the stipulations among teachers are towards teaching and learning. This is a fundamental question as it can tell something about teachers' stipulations about student's learning and their attitude towards fundamental goals of the reform.

An analysis of the teachers' point of view towards collaboration shows that they are generally more sympathetic towards teaching together in a cross disciplinary fashion than they are towards teaching isolated subjects such as English, history etc. without connections to other subjects. 70 percent of the teachers agree in statements expressing the importance of cross disciplinarily collaboration. This does not in any way indicate that teachers support the removal of specific subjects, but rather that they generally spoken seem to support a development towards new combinations of disciplinary and cross disciplinary teaching. But it should be noticed that a considerable minority of teachers do not believe that the reform discourse is positive, probably because they find coherence in the education as something to be build by the student himself and not by external structures such as cross disciplinary activities.

One of the arguments supporting an integration of different disciplines in more problem oriented learning processes is the importance of new competences among students in a world where combinations are being asked for. One teacher says:

Basically it is a human perversity to separate the subjects. Nature doesn't care.

A teacher, who is sceptic towards 'too much' dissolution of the single subjects, points out the danger that the students will not learn in a profound manner:

I feel a little that it hurts my professional pride that I can not explain things in a sufficient manner.

From the survey we can see that there seems to be some smaller differences between humanistic, social science and natural science teachers towards integration of disciplines, for instance in General Study Preparation, where the students are to work in a deductive way (which our survey by the way proves to be the reality??). 
Teachers in: $\quad$ Positive orientation towards integration of subjects

\begin{tabular}{||l|c|c|}
\hline \hline & High level of agreement & $\mathrm{N}$ \\
\hline \hline Humanities & $71 \%$ & 764 \\
\hline \hline Social sciences & $72 \%$ & 230 \\
\hline \hline Natural sciences & $61 \%$ & 415 \\
\hline
\end{tabular}

Teachers in the social sciences and humanities are the most sympathetic, while the teachers in natural sciences are the most sceptical. One reason for this is probably that project work as a work method is very close to the scientific methods within the field of social science, whereas a more systematically based theoretical way of thinking going from theory to experiments seems to dominate within the natural science. Whether the reason for this is epistemological differences between subjects or different traditions within subjects is difficult to say.

From the observations and interviews we see that the teachers - in spite of different levels of enthusiasm - at the moment are trying to create a balance between on the one hand systematic teaching in subjects and cross disciplinary teaching and on the other hand between deductive and inductive learning processes. The logic seems to be that the system of knowledge being contained within the single subject and specific epistemological tradition is important, because here you learn the methods and categories within a specialized domain. But also the more competence-orientated work where knowledge is being used to solve problems is important. It seems that the daily teaching in the Danish upper secondary school nowadays is actually carried through using much differentiated working methods. Classroom teaching, group work and project work seem to be the mostly used ways of teaching. The most common kind of teaching is a sequential process from classroom (explanation, example and so forth) over group work to plenum and class room dialogue. Project work is another matter, but it is often the result of a previous 'course' beginning with classroom teaching.

\section{The Study Plan and openness}

As mentioned earlier the reform indicates a change from curriculum based goals to competence based goals. And the teachers are asked to prove what the students learn. The Study Plan is to be used by the teachers themselves, by the students, by the management and for instance by parents wanting to know about the quality of the teaching at s specific school. It seems that The Study Plan is connected with a general policy of the government called "openness in the public administration", which again is related to the goal of making educational institutions more like a market place where the clients (students, parents) may examine what they get.

The qualitative research shows that from many teachers point of view The Study Plan is a bureaucratic construction, which does not create quality, being instead a 'time thief' and 'creativity killer'. One teacher says:

There is so much administration and paper work for teachers now. What I do is actually not very different from before, but it has to be put in to more or less artificial concepts such as 'competencies'.

The same teacher continues by saying that the consequence of all the documentation work are structures built on control and mistrust. There seems to be a opinion among teachers that they 
are met by politicians and sometimes by managers not believing that the teachers are doing their job well. One teacher says:

Somebody in the Ministry of Education, knowing nothing about us, has said: "We have to find out, if they know what they are doing. We will do it in this way". But I am a member of two or three teams, and they are to meet often, so ... Big Brother is watching you: some where some one is watching you, ... Interviewer: But who is it? Is it the management?

Teacher: Honestly? It is the abominable snowman. We write something, and no one is reading it. And when the students want to use it for their examination they can not find it. And they do not understand it.. I say: Why must we write them?

This teacher expresses feelings being relatively widespread among teachers. The approach to The Study Plan is related to a loss of security. The teachers are being watched over. They are not sure who is watching - but to write plans knowing that it is not being used by parents and students create a 'Kafka-like' feeling of absurdity. Probably, the logic behind the control phenomenon is to be found in the mechanisms of New Public Management, but from a teacher's point of view this is very far from the logic of teaching and learning.

Maybe the teachers' critique of this aspect of the reform has to do with the experience of teaching. From a teacher's point of view it is difficult to say what exactly students learn. Teachers facilitate learning processes and communication with students, but from many teachers point of view it is too instrumental to demand proof for the competences being learned. When politicians and The Ministry of Education demand documentation and evidence and use evaluations to secure the policy of effectiveness and openness, it can be experienced as being a very superficial affair from the teacher's point of view. So what from one perspective can be called a more tightly coupled organization seems from many teachers point of view to be a less efficient organization, partly because time and energy is put from teaching into organizational communication structures, partly because some teachers interpret some of the new evaluation and control systems as being demotivating in relation to the daily teacher work.

Another point to be made is that The Study Plan invokes frustration because it challenges the tacit knowledge of the traditional Upper Secondary School teacher - and it is a very visible manifestation of the organizational side of the teacher's work, which is not very developed in the traditional teacher identity. To communicate intentions and realizations among teachers seem to be necessary in a future with team work as a central dimension, but in the present situation ambivalence and insecurity towards the new seem too strong. One of the teachers being interviewed strongly believes in the reform project and can in no way be said to be resistant to changes. Actually, she finds the principles of the reform good for the students. But for the teachers' it has been "deeply problematic" and she continues:

We want to do it well. I want to do all the interdisciplinary stuff. And at the same time I must say that the old curriculum based teaching made me safe. You have to teach in this and this. Now they say that the students are to reach a competence in this and this and so on ... It's not concrete.

Interviewer: So it may also be a stress factor?

Teacher: It really is a stress factor. You don't know what to do. You don't know in detail what to do. And are you doing it right? You don't know. 
Because how

to evaluate it? But again: If the students can use it, then we teachers should be happy. But we are not happy. We are totally frustrated.

This kind of ambivalence seems to dominate many teachers' thinking. They are not opponents neither supporters of the reform - they are just trying to interpret the means and ends of the reform. This takes time, and it creates frustrations. The question is whether these frustrations are to be seen as necessary expenses in a change process, or whether there really is an overload and some control mechanisms in the reform which are contra productive.

\section{The teacher and the team}

Organizing in team is an explicit purpose with the reform emphasised according to the general rules from the ministry. This development is, also, a consequence of the larger extend of interdisciplinary content.

The actual implementation of team in the single school is, however, ambiguous. In some schools all teachers' on each school level are members of the same team, and in other schools team only consist of three persons, normally covering the three faculties, (natural sciences, social sciences and the humanities). However, common for all teams is that the main tasks are interdisciplinary collaboration and planning.

The question whether the teams can be filled with meaning and importance seems to be the cardinal issue in the implementation on schools. Is this development challenging the perception of autonomy from the teachers' perspective? Will there be different opinions towards the functional necessity of working with students study competences in a cross disciplinary perspective?

We do not in our survey ask if the teachers appreciate autonomy or not, but presented statements describing collaboration in team as a good and developing way of working as a teacher (the autonomy perspective) and a more controlling and restrictive working condition (the control perspective) respectively. Subsequently, two indices were constructed by means of factor analysis. The one index showed a positive outcome, and the other had a negative outcome of teamwork. The autonomy perspective contained items like "we gain advantages of our different competencies" and "we can share our experiences from the completed courses. The control index consists of items like "teamwork will restrict our conditions for flexibility, because we have to be more focussed in our planning" and "the detailed planning gives principals and colleagues possibilities for controlling my work".

The general pattern in the answers was a moderate bigger support for the autonomy index, although both indices has there majority in a medium degree of agreement. Among the most remarkable differences could be found when the perceptions are compared with sex, seniority, and the subject of teaching. The tendency that the greatest support for the autonomy index is found among female teachers, teachers with a relative low seniority (less than twenty years since graduation), and teachers teaching in humanities compared with teachers teaching in the natural sciences. An interesting observation is derived by a comparison of the perception of autonomy and control respectively with the factual experiences with teamwork. Teachers who inform they use more time on teamwork also report a lower the degree of agreement with the "autonomy discourse" and a larger degree of agreement with the "control discourse". 
According to Hargreaves (2000) teacher professionalism are at a crossroad, and not least in matter of collaboration and teamwork. On the one hand, a fruitful development and change from what he label 'the autonomous professional' to 'the collegial professional'. The autonomous professional had led to a condition of too much isolation, a situation not adequate for teacher development and to handle still more complex pedagogical tasks. On the other hand, if this "collegiality is forced or imposed, teachers can quickly come to resent and resist it” (Hargreaves 2000:166).

Certain conditions are required in the process of establishing teams. Teachers usually have had their focus on the students on the one hand and the curriculum on the other. In addition, their search for knowledge is traditionally directed towards colleges within the same discipline. These structures are vulnerable for changes if we consider teamwork in upper secondary schools as knowledge workers communities of practice (Nahapiet and Ghoshal 1998). Knowledge workers collaborate with a purpose of increasing the organizations total amount of intellectual capital. These communities of practice are dependent of structures as well of social relations. Beside the structural dimension, which often are decided by the management, it is also necessary to take into account a cognitive dimension (shared meaning and interpretations) and a relational dimension (norms, trust, expectations). To create fruitful teams need intellectual capabilities, motivation and a positive attitude to see the advantage with these teams.

These circumstances may explain some of the variations in the answers. Beside the actual differences in implementations of teamwork and the above mentioned 'stress-factor', one can maybe find scientific and methodological reasons for natural science teachers' resistance to cross-disciplinary teamwork compared with teachers' from humanities and social science.

The team-based structure of the organization creates a new culture. As mentioned, the schools move from a loosely coupled culture to more tight coupled culture. It has been said that the teacher culture earlier was built on a consensus where individuality and diversity was respected. However, how is this possible if you have to agree, for instance towards interdisciplinary projects? The team structure does not only make new kinds of meaning possible, but also new kinds of conflicts. A teacher says:

The problem is that you sometimes make an agreement about a project, but there are teachers who insist to do what they have always done. "I have taught in this way the last 15 years, and the reform is not going to change that". I had a problem with a teacher. He insisted to do what he used to do. The result was that his teaching not at all suited our common project. There was no professional reason why he should do like he did, but he insisted to do like he used to".

Furthermore, there is a risk for challenging teachers individual autonomy in the classroom. As a headmaster pointed it out:

"Maybe teachers fear the collaboration. Maybe they can become responsible for assessing each others work!!"

Another aspect of the cultural dimension is related to the understanding of teachers' as one homogeneous group in the organizational hierarchy. Membership of teams (and formal and informal positions as team leaders) leads to new and dividing levels with different (formal as well as informal) status. 


\section{Teachers' positions towards management}

The development described above makes it clear that schools are to be considered as organizations with shared ends and tasks. The traditional organizational structure of schools can be seen as a 'bureaucracy' with professionals (Mintzberg 1983). Teachers have been responsible towards the official documents, rules of examinations and their professional networks, often placed outside the school. Methods and didactical procedures are traditionally been considered as the responsibility of the single teacher.

The sixteen questions were by factor analysis grouped in four indices. 1) the administrative leader (e.g. following rules, timetabling), 2) the personal leader (e.g. take a position in relation to teachers entire life, solve problems in relation to teaching, be a personal councillor) , 3) the organizational leader (e.g. take a position in relation to teachers teaching and other tasks, be in charge of school development, develop shared values), and 4) the external oriented leader (e.g. public meetings in local communities, public medias, public communication about the schools specific profile).

\begin{tabular}{|l|c|c|}
\hline & High level of agreement & $\mathrm{N}$ \\
\hline \hline $\begin{array}{l}\text { The administrative oriented } \\
\text { management }\end{array}$ & $95 \%$ & 1700 \\
\hline \hline The personal oriented management & $20 \%$ & 1680 \\
\hline $\begin{array}{l}\text { The organizational oriented } \\
\text { management }\end{array}$ & $74 \%$ & 1694 \\
\hline The external oriented management & $47 \%$ & 1674 \\
\hline
\end{tabular}

An analysis of the survey shows, that the teachers with a considerable majority, confirms two types of management. We label the first 'administrative management' and it is identical with the classical transactional management, which means, that the 'administration' makes it possible for the professionals to do their work, for instance by making an effective timetable. Nevertheless, this should not be considered as a kind of regression to old historical positions, because when the complexion of the school organization groves, the need to find new structures seems to grow too. This tendency is a kind of re-bureaucratization, which can recreate a kind of stability on a new historical level.

Another area for management efforts - from a teacher perspective - is a more organizational orientated management. The organizational orientated management is occupied with organizational development by relating to the teaching of teachers and development of common values.

The patterns did not differ for the background variables, but especially concerning organizational management, variations are observed. When we took gender and seniority in regard, we could see that female and younger teachers, compared with male and 'older' teachers considered the organizational perspective as more important.

Nevertheless, teachers also seem to deny or to approve less to certain kinds of management. They do not support the personal orientated management, where the leader functions as 
supervisor, coach and mentor. An explanation could be teachers in upper secondary school considering them selves being professionals that do not need leaders 'close to them'. A human resource management therefore seems to have huge difficulties in the school world.

Considering specific results it seems that the younger the teachers are, the bigger confirmation there is to the organizational orientated leadership. An explanation here could be that younger teachers are less socialized to an organisation culture, where the professional teacher on his or her own is the ideal. Another interesting point is that the world orientated management finds bigger confirmation among teachers in small towns than in bigger towns. Probably the explanation is that the local environment is more important in smaller towns. Here the school really has to expose itself in order to survive.

There seems to be some frustrations towards the missing communication structures between the management and the teachers. Especially the loss of some kind of common meetings with all teachers as participants is pointed out as a problem; the teams is now filling out the meeting-space, but the teams can easily become small 'islands', with no connections. So the big problem is the missing spread of knowledge. It also is difficult for some teachers to accept the new gap between leaders and teachers. One teacher says:

\section{"We have democracy as a key word, and many decisions are actually being delegated - but there is much more management than before"}

Another teacher finds it very problematic that a kind of amateurism in reality is taking over, when teachers are to be leaders without having neither the formal or practical competences to take decisions. The same teacher worries about a discourse, which she find many places where the school is discussed. It says that everything new is good, and every thing old is bad. On these terms it seems to her very difficult to maintain continuity in the system and as teacher to use an experience.

For that reason, we are looking at managing teachers as managing professionals. Teachers in Danish upper secondary do all have a university degree, and due to socialisation during education and professional career, most professionals develop and maintain a strong identity connected to their skills and knowledge. The specific degree and form of teacher professionalism are subject to an ongoing debate (Realin 1985, Hargreaves 2000, Nixon et al. 1997)

The dilemma between shared planning and the work of professionals can lead to a situation, which has been labelled "the clash of cultures" (Raelin 1985). Essential characteristics that may be perceived as resistance to management are: a) autonomy over ends as well as means, or at least over means, b) overspecialization, c) bureaucratic vs. professional standards and evaluation, d) a lack of respect for the 'real world', and e) a lack of respect for organizational procedures (Raelin 1985). These dimensions are not represented with the same importance in our project, but they exist as basic assumptions for leadership conditions in Danish upper secondary schools.

The development requires leadership and management. However, leadership and management are ambiguous tasks, and how and where to practice it is a subject for decision and implementation. Traditionally there has been a kind of sceptic attitude from teachers towards management. 


\section{Conclusions and perspectives}

The reform of the Danish upper secondary school can be seen as a very ambitious project being driven by certain strategies from 'above'. The reform makes the organisation more complex. The political level asks for a management that can guarantee the implementation of the reforms. The Danish minister of education talks about a new management culture in schools.

The reform demands for organizational development head towards tighter couplings (Weick 1976; Orton and Weick 1990). An important trend in the reform is teambuilding as an organisation answer to the more complex nature of the organisation and the learning processes involving cross disciplinarily teaching. We can observe a change from loose couplings between individuals to loose couplings between subunits; in this case teams.

And structurally spoken the more tight couplings between teachers and subjects to teach require new managerial skills (Hargreaves 2006; Spillane 2006). Thus with the reform the function of management is changing. New structures demand new ways of organizing the schools. Also is the demand for documentation, which is a very dominant feature of the reform, is here worth mentioning, because it seems to be an important management tool in the future. Therefore the single school in the future can be considered as an organizational unit. Theses changes seem to create some frustration, which goes in more than one direction.

The combination of changes within and changes from without are significant - and the question is how the teachers will react. In many ways this is the central group in a reform process. The leaders are employed to carry through the reform, and the students belong to the institution. The teachers are there to be led by leaders and to lead students. The reform actualises a schism between structure and culture. Of cause you change a culture by making new structures. But is it being changed for the better? From our data's we can see that it is too early to say what will happen. The picture is not clear. More than one teacher culture seems to be the result in a kind of symmetry with different management strategies.

One important issue seems to be the meaning teachers can find in 'the new'. Do they feel that their teaching is improved by the new dimensions? In this respect the reform pose more questions than it asks. Is the time being used well? Is there a necessity in the cross disciplinary activities, or is it something you do by plight.

The organizational development represents a potential paradox. From one point of view, we have a structure based on - in comparison with the former structure - relative autonomous team. Teachers in the team are experts, and they are largely responsible for planning and completion of teaching courses. From the other point of view, this process of planning and evaluation lead to control and restrictions. This ambiguous outcome was also represented in our survey discussed in chapter 4.

The development leads to changed leadership tasks. Leaders may interpret the clash of cultures between reform-rationality and teachers' thinking. They may capture a development towards an organizational oriented leadership. The challenges are how to manage new couplings without hurting the 'core competences' (i.e. teaching and relations to students)? Following this dilemma is building frames for meaning creation, to support teachers' double belonging to various communities of practice (e.g., their discipline and their (cross 
disciplinary) project team). A potential and existent mistrust towards the reform-rationality demands a bigger effort for creating an environment with mutual trust and shared values.

Another important issue is the relation between the new team structures and school development. In many teachers mind there seems to be a past of democracy and a present of some kind of totalitarian government of the schools. The reason why seems to be complex. One reason is that the past seems to be idealized, because in the 'good old days' there seemed to be a kind of informal power because of the egalitarian culture. Another reason seems to be a tendency towards fragmentation. The meetings are certainly being more and the same are the decentralized decision - but where do teachers discuss all of them?

And last, but not least the teacher identity seems to be challenged by a system thinking which removes spontaneous moves from the single teacher. If the old identity was that 'here we aggress that the single teacher should do tings in his own way', the new systems has a tendency towards a group thinking which does not fit the teacher habitus.

The many modes of reactions among teachers challenge leadership in the post modern school. From our material we can see to kinds of reaction. One is to make new forms of negotiations between leaders and teachers, as in distributed management. Here the problem can be a decentralized structure with tendencies towards balkanization (Hargreaves 2003). Another is a strong strategic leadership, where the teachers are treated as employees in an order-driven mode. The problem here can be that you in reality make a 'factory workers' consciousness among the teachers with not enough power to make innovation. In both cases the problem can be leaders leading schools being so complex that the organizational consciousness becomes bigger than the consciousness concerning the teaching and learning culture in the class.

From the teachers point of view there still exist bridges to be gapped between the classroom and the organization. The structural framing of new relations is a reality - the school culture being the result of the structural pressure on the culture is still to be seen.

\section{References}

Bourdieu, P. \& Passeron, J. (1970/1996) Reproduction in Education, Societyand Culture. London: Sage Publications.

Gibbons, M., Scott, P., Nowotny, H., Limoges, C., Schwartzmann, S., and Trow, M. (1994).

The New production of Knowledge: The Dynamics of Science and research in

Contemporary Societies. London: Sage.

Hargreaves A. and Fink, D. (2006). Sustainable Leadership. San Francisco: Jossey-Bass

Hargreaves, A. (1994) Changing Teachers, Changing Time. London: Cassell, Villiers House.

Hargreaves, A. (2003) Teaching in the Knowledge Society: Education in the Age of Insecurity. New York: Teachers College Press.

Honneth, A. (2003) Behovet for anerkendelse. En tekstsamling. København: Hans Reitzels forlag.

Klafki, W.(1976). Aspekte kritisch-konstruktiver Erziehungswissenschaft. Weinheim.

Lave, J. og Wenger, E. (2003) Situeret loering og andre tekster. København: Hans Reitzels Forlag.

Luhmann, N. (1984) Soziale Systeme. Frankfurt am Main.

Moran, J. (2002). Interdisciplinarity. London: Routledge. 
Nahapiet, J and Ghoshal, S. (1998) Social capital, intellectual capital, and the organizational advantage. Academy of Management Review 23 (2), 242-266.

Orton, J.D. and Weick, W. (1990) Loosely Coupled Systems: A Reconceptualization. Academy of Management Review 15 (2), 203-223.

Piaget, J. (2000) Ligevægtsbegrebets rolle i psykologien (1959), in: Illeris, K. (red.). Tekster om loering. Frederiksberg: Roskilde Universitetsforlag.

Spillane, J.P. (2006). Distributed leadership, San Francisco: John Viley and Sons.

Vygotsky, L.S. (2006). Mind in Society - The Development of Higher Psychological Processes. Harvard University Press.

Weick, K. E. (1976) Educational Organizations as Loosely Coupled Systems", Administrative Science Quarterly, Vol. 21.

Ziehe, T. og Stubenrauch, H. (1983) Ny ungdom og uscedvanlige loererprocesser: kulturel friscettelse og subjektivitet. København: Politisk revy. 